\title{
Effective of Educational Instruction of Nurses Knowledge Regarding Meningitis and Universal Precaution Measures at Selected Department at Minia Fever Hospital
}

\author{
Nemaat A. Hussien ${ }^{1}$, Yosria E. Hossein ${ }^{2}$, Mona Abouzed Khalifa ${ }^{3}$ Amal H. Mohammed ${ }^{4}$ \\ 1. B.Sc. Nursing, Faculty of Nursing, Minia University, \\ 2. Professor of Community Health Nursing, Minia University, \\ 3. Prof. of Public Health and Preventive Medicine Faculty of Medicine- Minia University, \\ 4. Lecturer of Community Health, Faculty of Nursing, Minia University
}

\begin{abstract}
Background: Meningitis is an inflammation and swelling of the membranes that cover the brain and spinal cord. These membranes are called meninges. Meningitis is most often caused by an infection. This disease can be fatal or cause serious lasting side effects. Meningitis is an infection that causes inflammation of the meninges Aim: The study aimed to assess effectiveness of educational instruction of nurses' knowledge regarding meningitis and universal precaution measures at Minia Fever Hospital. Study design: A descriptive cross-sectional research design was utilized in this study. Subject: A convenient sample of 50 nurse were selected from all departments (kidney department and pediatric department, outpatient, inpatient unit for infectious disease as typhoid fever, puerperal sepsis, meningitis and hepatitis A virus), who divided into 14 nurses had bachelor degree, 10 nurses had diploma in nursing and 26 nurses had Technical institute. Setting: This study was carried out at Fever Hospital in Minia city. Tools: Three tools were utilized in this study, The First Tool; was an interviewing structured questionnaire sheet concerned with the socio-demographic characteristics about studied nurse. Second Tool; was concerned with nurses knowledge Assessment questionnaire about meningitis, including of (18) questions. Third Tool; include Knowledge assessment tools regarding universal precaution of meningitis, it consisted of (30) questions. Results The most of study subjects have unsatisfactory level of knowledge about meningitis with mean scores of $9.3 \pm 2.7$ and most of study subjects have good knowledge about universal precautions regarding meningitis with mean scores of $24.4 \pm 6.8$. Conclusion: the most of study subjects have unsatisfactory level of knowledge about meningitis and less than fifth have satisfactory level of knowledge about meningitis and the most of study subjects have good knowledge about universal precautions regarding meningitis. Recommendations: Encourage the nurses to participate in training courses held by specialists in meningitis to update their knowledge and increase nurse's knowledge and updated in pediatric unit in the hospital with the current researches and guidelines by taking a training course.
\end{abstract}

Keywords: Educational, Nurses, knowledge, Meningitis, Universal Precaution

\section{Introduction}

Meningitis is a devastating disease with many deaths and significant long-term sequelae in survivors and remains a major global public-health challenge. Cases and outbreaks are a threat in all countries of the world. Meningitis is an inflammation of the membranes that surround the brain and spinal cord. It is predominantly caused by infection with bacteria and viruses. Infection with fungi and parasites can also cause meningitis, with cryptococcal meningitis having an increasing importance among adults living with human immunodeficiency virus. Meningitis can also develop as a result of non-infectious factors, including certain medications, cancer and autoimmune diseases (World Health Organization, 2019).

The World Health Organization indicates that each year registers nearly half a million new cases suffering from meningitis. In Egypt, the total cases of meningitis registered in 2011 were higher than those registered in 2010 (the total number of cases were 1400 and 1394 respectively) and the number of infected patients who are less than fifteen years of meningitis in 2011 is equal to 800 have greater than the number of the infected patient in 2010, which is equal to 759 . As in the governorate of Qaliubiya, the number of patient with meningitis in 2011 has reached 48 patient (El Kareh et al., 2020).

Meningitis is a term used to describe an inflammation of the membranes that surround the brain or the spinal cord. Meningitis, especially bacterial meningitis, is a $P$ a g e | 117 potentially life-threatening condition that can rapidly progress to permanent brain damage, neurologic problems, and even death. The highest incidence of meningitis is between birth and two years, with the greatest risk immediately following birth and at three to eight months of age (Hassan et al., 2020).

Bacterial meningitis is a medical emergency characterized by inflammation of the meninges in response to bacterial infection. Untreated, its mortality approaches $100 \%$, and even with current antibiotics and advanced pediatric intensive care, the mortality rate of the disease is approximately $5-10 \%$. Worldwide, the risk of neurological squeal in survivors following hospital discharge approaches $20 \%$. Early diagnosis and appropriate management of the patient with meningitis is therefore critical (Rajan and Karen, 2019).

Meningitis can be complicated with several neurological and systematic complications. The complication includes shock, myocarditis, and status epileptics, subdural empyema or effusion, ventriculitis, hydrocephalus or neurological defitus, ocular palsies blindness speech problem, deafness obesity, and precocious puberty. The triage nurse must be fully aware of the signs and symptoms of the disease and refer the patient immediately to the emergency room physician ( Hasbun et al., 2017).

The most important and significant factor in the survival of patient with meningitis is the standard of nursing care provided to meet their requirements. Thus, the nurse must possess abroad knowledge for different methods of care for

Nemaat A., et al 
patient with meningitis and practical skills in the application of therapies directed toward solving of the problems that patient exposed to invasive procedures (Nguce, 2018).

Prevention and control of infections are important concerns for all types of health care agencies. The infection control practitioner is usually a nurse with advanced training in infection control practices and spread of infections. An assessment of the knowledge, attitude and practice of standard precautions by healthcare workers is a prerequisite for initiating and implementing a successful infection prevention and control strategy in any health facility. Knowledge and training in standard precautions and high risk perception have all been associated with improved compliance with standard precautions among health workers (Barrera et al., 2019).

Nurses play an active role in the control and management of meningitis through early observation, diagnosis and by following a defense inverse infection technique. Therefore, nurses should be trained through continuous educational programs to upgrade their knowledge level and improve their practical skills regarding control and management of meningitis. Nurses needs to teaching program to increase the knowledge and skills and be able to deal with acute meningitis patients (Obaid et al., 2016).

The educational instruction for nurses provides a comprehensive plan that demonstrates the feasibility of the program and ensures that nurses are able to meet the applicable standards and competencies. The nursing teaching program provides the content that ensures receive the theoretical and clinical practice experiences required to meet the applicable standards and competencies. The program provides quality to nurses in order to meet the applicable standards and competencies. The nursing teaching program has formal systems and processes in place to measure nursing performance as well as program effectiveness (Mohammed, 2019).

\section{Significance of the study:}

The incidence and case-fatality rates of bacterial meningitis vary according to country, region, pathogen, and age group. Without any treatment, the case-fatality rate can reach $70 \%$, and one in five survivors of bacterial meningitis may be left with a permanent disability including hearing loss, neurologic disability, or limb loss . Routine vaccination against the three most common causative bacterial pathogens had a considerable effect on the prevalence of bacterial meningitis. However, an estimated 1-2 million cases of bacterial meningitis occur worldwide every year, resulting in 180000 deaths in children age from one to 59 months in 2010. The epidemiology of acute bacterial meningitis has changed markedly since the introduction of conjugate vaccines (Allam \& Morad, 2016).

Meningitis is considered as an endemic disease in Egypt. Apart from endemicity, a violent periodic epidemic occurs every 6-12 years in the African meningitis belt. Endemic meningitis among children takes the form of sporadic cases or small clusters with an endemicity rate of $1.5 / 100,000$ and 20/100,000 population in the developed and developing countries, respectively (Zelano \& Westman, 2020).

Study was approved by the Council of the Public Health Department Faculty of Medicine, Cairo University، and Ministry of Health and Population Staff. Incidence risk of meningitis disease in Egypt represented ( 58\%) and in Minia (19\%). per 100000 population (Abdel-Razik et al., 2017)

\section{Aim of the study}

The aim of this study is to assess educational instruction effective of nurses regarding meningitis universal precaution measures at Minia Fever Hospital.

\section{Research Questions:}

- What is the level of knowledge for nurses regarding meningitis?

- What is the global precaution for nurses regarding meningitis?

\section{Subjects and methods}

\section{Research design:}

A descriptive cross-sectional research design was utilized in this study.

\section{Setting}

The study was conducted at Fever Hospital in Minia City, it is located in Minia city at Masaken area and contains 119 beds. A fever hospital is a hospital for infectious diseases such as scarlet fever and smallpox. Fever hospital treat affected people with infectious diseases and isolate them from the general population to prevent spread of infection, they provide a wide range of health care services for the urban and rural population in Minia city.

Sample:

A convenient sample of 50 nurse were selected from all departments (kidney department and pediatric department, outpatient, outpatient unit for infectious diseases such as typhoid fever, puerperal sepsis, meningitis and hepatitis A virus), who divided into 14 nurses had bachelor degree, 10 nurses had diploma in nursing and 26 nurses had Technical institute.

\section{Inclusion criteria:}

- All nurses from both sex

- All educational levels of nursing.

\section{Data Collection Tools:-}

Tool I: interviewing Questionnaire:-

Tools for data collection were consisted of three tools:-

Tool I: Structured interview questionnaire: developed by the investigator to collect data related to; Nurse's personal data questionnaire including nurse's demographic characteristics. Including (11) open ended question about nurse such as age, gender, residence, years of experience, participation in the training courses, number of training course and place of training, direct contact with infected people, the nature of your work increase the risk of infection and taking preventive action.

- Tool II: Knowledge Assessment questionnaire for meningitis : It consisted of (18) questions to assess of nurses' knowledge about meningitis such as definition, causes, risk factors, signs and symptoms, first symptoms of meningitis, how does someone get meningitis, with multiple choice response, preventive measures regarding meningitis: such as vaccine, good hand hygiene. 
- Tool III: Knowledge Assessment Tools for universal precaution: It consisted of (30) questions to assess nurses knowledge about universal precaution such as: (hand hygiene, gloves, gown), with response of done or not done (Shivani \& Rashmi, 2019).

\section{Scoring system:-}

- For knowledge outcomes, correct responses was scored as (One), while incorrect responses will be scored as (Zero). The total knowledge score was 12 Scores $\leq 12(60 \%)$ will classified as unsatisfactory level of knowledge, scores $>12(60 \%)$ will classified as satisfactory level of knowledge (Shivani \& Rashmi, 2019).

For universal precaution outcomes, correct responses was scored as (One) while incorrect responses will be scored as (Zero). The total practice scores was (30). Scores $>18(60 \%)$ was classified as good practice Scores $\leq 18(60 \%)$ was classified as poor practice (Shivani \& Rashmi, 2019).

\section{The Validity of the Tool:}

The tools will be exposed to a panel of experts (5) in the field of community health nursing to test their content validity, the instruments were examined, and any modifications were done in the light of the comments of the members conducted of the jury.

\section{Pilot Study:-}

The pilot study was conducted before the actual collection of data began, in order to examine and ensure the feasibility, objectivity, applicability, consistency and sufficiency of the research tools and to recognize potential problems in the methodological methodology or instrument, $10 \%$ of participants were involved. The outcomes of the pilot study were used to assess the methods of statistical and data analysis proposed. Without trouble, the tools were completed, providing additional support to the validity of the instrument. The requisite corrections and changes have been made. The pilot study were included in study subjects.

\section{Data Collection Procedure:-}

- An official letter was sent from the Dean of the faculty of Nursing at Minia University to head manager of Fever Hospital, for permission to collect data. Once permission was taken the investigator started data collection. Editing

- Meeting with the hospital manager to explain the objectives and aim of the study that will help to gain their cooperation and to allow meeting with nurses during minimal work load activities.

- To collect data from nurses, the investigator explain the aim and nature of study and how to fulfill this questionnaire briefly through direct personal communication.

- The investigator met participants in their work at times that were convenient for them. According to the appropriate clarification, the time spent completing the questionnaire ranged from 25 to 30 minutes, after outlining the significance and purpose of the research. Every nurse was allowed to ask any question to clear any misunderstanding.

- Oral consent was obtained from the participants before inclusion in the study, after that the investigator was distributed all questionnaires to nurses who agreed to participate in the study and asked them to fulfill it, also the investigator waited with nurses during fulfillment the questionnaires for any questions.

- The investigator visited fever hospital to collect the data in two days each week, for. The data were collected through about three months from the first of October 2020 to 30 December 2020, two day/week at official work time from 9Am: $12 \mathrm{Pm}$

\section{Ethical Consideration:}

The nurses were informed that their participation in the study was completely voluntary and that there was no harm if they didnot participated in the study. Oral_consent was taken to be included in the study subject. Explanation about the study was done to the nurses included the aim of the study and the potential benefits. The participant was informed about the withdrawal procedures if they decided to leave the study at any time before and during the completion of data collection, confidentiality of data, privacy, identity, voluntary participation, and the right to refuse to participate in the study was emphasized to subjects.

\section{Statistical Analysis}

Version 20 of the statistical package for social science was used to collect, tabulate, and analyse the data. Numbers and percentages were used to represent descriptive variables. The mean and standard deviation were utilized to present quantitative data. Chi square test was used see if there were connection between two qualitative variables or if there was a difference between two or more proportions. Correlation was used. Significant at (p-value $<0.05$ ).

\section{Results}

Table(1): Distribution of Socio Demographic Characteristics of Study Participants (n=50)

\begin{tabular}{|cl|c|c|}
\hline sex: & Male & 28 & 56.0 \\
$\bullet$ & Female & 22 & 44.0 \\
\hline Age: & $20<29$ & & \\
$\bullet$ & $30<39$ & 11 & 26 \\
$\bullet$ & $40<49$ & 6 & 12.0 \\
$\bullet$ & $>50$ & 7 & 14.0 \\
\hline \multicolumn{3}{|c|}{ Mean age 29.4 11 11.1 years. } \\
\hline
\end{tabular}




\begin{tabular}{|c|c|c|}
\hline $\begin{array}{l}\text { Educational level: } \\
\text { - Secondary } \\
\text { - Technical institute } \\
\text { - University } \\
\end{array}$ & $\begin{array}{l}10 \\
26 \\
14\end{array}$ & $\begin{array}{l}20.0 \\
52.0 \\
28.0\end{array}$ \\
\hline 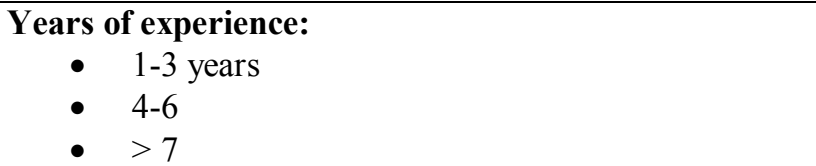 & $\begin{array}{l}16 \\
20 \\
14\end{array}$ & $\begin{array}{l}32.0 \\
40.0 \\
28.0\end{array}$ \\
\hline $\begin{array}{l}\text { - Participation in the training course: } \\
\text { - Yes } \\
\text { - No }\end{array}$ & $\begin{array}{l}38 \\
12 \\
\end{array}$ & $\begin{array}{l}76.0 \\
24.0 \\
\end{array}$ \\
\hline $\begin{array}{l}\text { Place of training } \\
\text { - Inside hospital } \\
\text { - } \text { Outside hospital } \\
\text { - Inside and outside hospital }\end{array}$ & $\begin{array}{c}31 \\
7 \\
12 \\
\end{array}$ & $\begin{array}{l}62.0 \\
14.0 \\
24.0\end{array}$ \\
\hline $\begin{array}{l}\text { Direct contact with infected persons } \\
\qquad \quad \text { Yes } \\
\qquad \quad \text { N0 }\end{array}$ & $\begin{array}{c}45 \\
5\end{array}$ & $\begin{array}{l}90.0 \\
10.0\end{array}$ \\
\hline $\begin{array}{l}\text { The nature of your work increase the risk of infection: } \\
\text { - Yes } \\
\text { - No }\end{array}$ & $\begin{array}{c}41 \\
9\end{array}$ & $\begin{array}{l}82.0 \\
18.0\end{array}$ \\
\hline $\begin{array}{l}\text { Taking preventive action (universal precaution) } \\
\qquad \quad \text { Yes } \\
\bullet \quad \text { No }\end{array}$ & $\begin{array}{c}41 \\
9\end{array}$ & $\begin{array}{l}82.0 \\
18.0\end{array}$ \\
\hline
\end{tabular}

Table (1) shows that, $56 \%$ of study subjects were males and $44 \%$ are female. Regarding age, $52 \%$ their age ranged from 20 years to 29 years, $12 \%$ their age ranged from 40 years to 49 years with mean age $29.4 \pm 11.1$ years. Their educational level reveals that, $52 \%$ have technical institute and 28\% have university degree and 20\% have secondary degree. Regarding Years of experience, $40 \%$ have 4 to 6 years of experience and $28 \%$ of study subjects have more than 7 years. $76 \%$ participate in the training course with $62 \%$ trained inside hospital and $90 \%$ of study subjects have direct contact with infected persons. Also $82 \%$ of study subjects the nature of their work increase the risk of infection and take a preventive action.

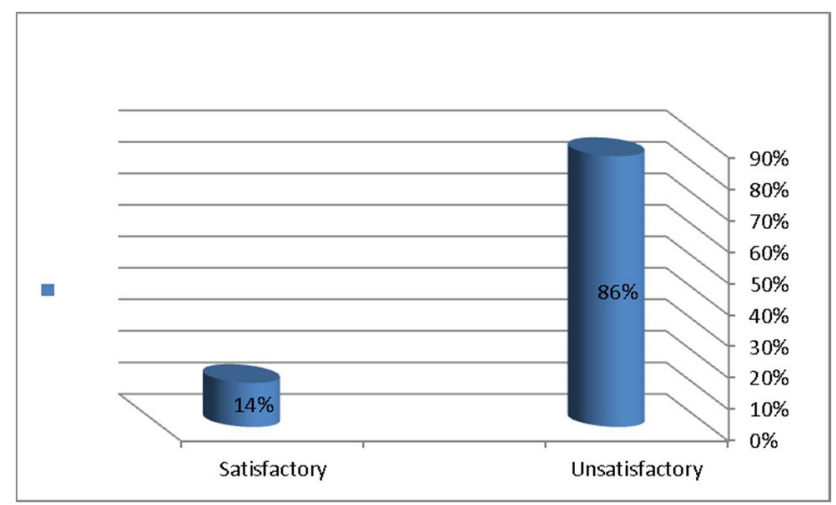

Figur (1): Distribution of Study subjects according to their Total knowledge about Meningitis $(\mathrm{n}=\mathbf{5 0})$

Figur (1), shows that $86 \%$ of study subjects have unsatisfactory level of knowledge about meningitis and $14 \%$ have satisfactory level of knowledge about meningitis.

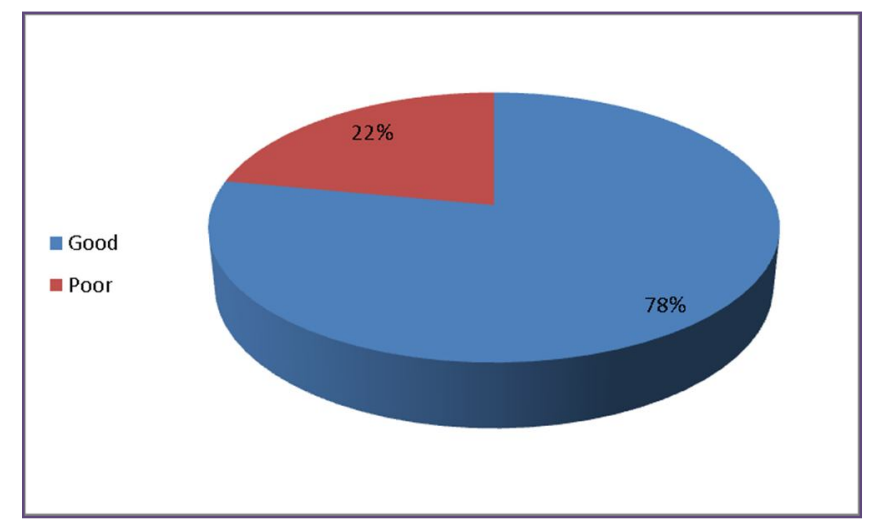

Figure (2) Distribution of Study subjects according to their Total knowledge about Universal precautions regarding Meningitis $\mathbf{n}=\mathbf{5 0}$ 
Figure (2), shows that $78 \%$ of study subjects have good knowledge about universal precautions regarding meningitis but $22 \%$ of them have poor knowledge about universal precautions regarding meningitis.

Table (2) Distribution of Study subjects according to their Total knowledge scores about Meningitis and universal precautions $(\mathbf{n}=\mathbf{5 0})$

\begin{tabular}{|c|c|c|}
\hline & & \\
\hline$\bullet \quad$ Satisfactory & 33 & 66.0 \\
\hline Unsatisfactory & 17 & 34.0 \\
\hline Mean \pm SD & $33.6 \pm 8.9$ & \\
\hline
\end{tabular}

Table (2) shows that $66 \%$ of study subjects have a satisfactory level of knowledge about meningitis and universal precautions and $34 \%$ have an unsatisfactory level of knowledge about meningitis and universal precautions with mean scores $33.6 \pm 8.9$.

Table (3): Correlation between total knowledge and Years of experiences of The Study Subjects $(\mathrm{n}=50)$

\begin{tabular}{|l|c|c|}
\hline \multirow{2}{*}{} & \multicolumn{2}{|c|}{ Total knowledge score } \\
\cline { 2 - 3 } & Correlation Coefficient (r) & P-value \\
\cline { 3 - 3 } & .0448 & $0.001 * *$ \\
\hline Years of experiences & & \\
\hline
\end{tabular}

N.B significant is considered at ( $p$-value $<0.05$ ).

Table (3), shows that there are highly statistical significant differences in knowledge and years of experiences, $\mathrm{P}$ value $=.001$.

Table (4): Relation between Total knowledge scores and Demographic characteristics among the study Subjects ( $\mathrm{n}=50$ )

\begin{tabular}{|c|c|c|c|c|c|}
\hline \multirow[t]{3}{*}{ Sex } & \multicolumn{4}{|c|}{ Total knowledge $(\mathrm{N}=50)$} & \multirow{2}{*}{ P. value } \\
\hline & \multicolumn{2}{|c|}{ Satisfactory } & \multicolumn{2}{|c|}{ Un satisfactory } & \\
\hline & $\mathrm{N}$ & $\%$ & $\mathrm{~N}$ & $\%$ & \\
\hline - $\quad$ Female & 19 & 38.0 & 9 & 18.0 & $.03 * *$ \\
\hline - $\quad$ Male & 14 & 28.0 & 8 & 16.0 & \\
\hline \multicolumn{5}{|l|}{ Age } & \multirow{5}{*}{$\begin{array}{c}\mathbf{X}^{2}=72.6 \\
.000 * *\end{array}$} \\
\hline - $20-29$ & 22 & 44.0 & 4 & 8.0 & \\
\hline - $\quad 30-39$ & 9 & 18.0 & 2 & 4.0 & \\
\hline - $40-49$ & 4 & 8.0 & 2 & 4.0 & \\
\hline - $\quad$ More than 50 & 7 & 14.0 & 0 & 00.0 & \\
\hline \multicolumn{5}{|l|}{ Educational Levels } & \multirow{4}{*}{$\begin{array}{c}\mathbf{X}^{2}=53.9 \\
.001 * *\end{array}$} \\
\hline - $\quad$ Secondary & 4 & 8.0 & 6 & 12.0 & \\
\hline - $\quad$ Technical institute & 1 & 2.0 & 25 & 50.0 & \\
\hline - $\quad$ University & 10 & 20.0 & 4 & 8.0 & \\
\hline
\end{tabular}

Table (4) reveals that, there is a positive statistically significant difference was found between total knowledge scores and demographic characteristics of the study subject's sex, age and their education level respectively. p value $.03 * *$ and $.001 * *$.

\section{Discussion}

The aim of this study is to assess educational instruction effective of nurses regarding meningitis universal precaution measures at Minia Fever Hospital.

The present study showed more than half of the studied sample was males, more than half of them their age ranged from 20 years to 29 years, with mean age $29.4 \pm 11.1$ years. Concerning the educational level the present study showed that more than half of the studied sample had technical institute and less than one third had university degree. As regarding Years of experience, less than half of them had 4 to 6 years of experience and less than one third of them have more than 7 years and the most of them had participated in previous training course inside hospital.

This result comes in accordance with (Zaki and Hussien, 2017) who studied "impact of an educational program on improving nurses knowledge and practice concerning caring for children with meningitis" and reported that less than half of the nurses their age ranged from 24-28 years with mean age (27.19 \pm 8.77$)$. The majority of the studied nurses had years of experience ranged from 5-10 years with a mean duration of 9.88 and the most of them had educational program courses related to emergency need.

Also the current study come in the line with (Elnageeb, 2018) who studied " Assessment of Nurses Knowledge Regarding Care Of Child with Meningitis in Soba university hospital $(2017$ - 2018)" and reported that the most of the studied sample had more than 3 years' experience. But the current study contraindicated with the same author in reporting that the majority of the studied sample was female and had bachelor degree.

But the present study differ with (Atshan and Aburghif, 2016) who studied "Effectiveness of an Educational Program on Nurses' Knowledge toward Children with Meningitis at Pediatric Teaching Hospitals in Baghdad City" and reported that more than half of the sample were females with equal percentage for the study and control group, and less than half of the nurses were in age group of 20-29 
years old and the half of them for both groups were graduated from the secondary nursing school.

Regarding the Total knowledge about Meningitis, the present study showed that the most of study subjects have unsatisfactory level of knowledge about meningitis and less than fifth have a satisfactory level of knowledge about meningitis. This may be due to lack of appropriate courses in the curricula of institutions.

This result come in line with (Kafl and Bayoumi, 2019) who mentioned that the most of the studied sample had poor knowledge about meningitis. Also this result come in accordance with (Oladele, Jorddan et al., 2020) who studied Tackling cryptococcal meningitis in Nigeria, one-step at a time; the impact of training and reported that the most of the studied sample had poor knowledge regarding meningitis.

Concerning total knowledge about universal precautions regarding meningitis, the current study showed that the most of study subjects have good knowledge about universal precautions regarding meningitis. This may be due to effective health education from the infection control team.

This result supported by (Moyo, 2013) who studied " Factors Influencing Compliance with Infection Prevention Standard Precautions among Nurses Working at Mbagathi District Hospital, Nairobi, Kenya" and reported that the nurses had adequate knowledge and practices regarding the basic elements of infection prevention and standard precaution.

This result contraindicated with (Gawad, 2017) who studied Assessment of knowledge about standard precautions and nosocomial infection among nurses working in hospitals of Sana'a city, Yemen " and reported that more than half of the studied sample had inadequate knowledge regarding universal precaution. But this result come inconsistent with (Hassan et al., 2020) who studied "Infection Control Knowledge and Practices: Program Management in Labor Units According to Standard Infection Control Precautions in Northern Upper Egypt" and reported that more than half of the studied nurses had poor knowledge regarding standard precaution.

Regarding the total knowledge scores about meningitis and universal precautions, the present showed that more than two third of study subjects have satisfactory level of knowledge about meningitis and universal precautions. This may be due to that the most of the studied sample Participate in the training course. But this result come inconsistent with (Atshan and Aburghif, 2016) who studied " Effectiveness of an Educational Program on Nurse's Knowledge toward Children with Meningitis at Pediatric Teaching Hospitals in Baghdad City" and mentioned that nurses have fair knowledge about meningitis

Regarding the correlation between total knowledge and years of experiences of the study subjects, the present study showed that there are highly statistical significant differences in knowledge and years of experiences. This may be related to that the nurse who had more years of experience was learn more skills and knowledge more than those who had less years of experience.

This result come in the line with (Atshan and Aburghif, 2016) who reported that there is significant relationship between nurses' knowledge and years of experience in nursing for the study group at $\mathrm{p}$-value $=0.05$. also this result were supported by ( Hattab, Kadhim et al., 2017) who mentioned that there were significant relationship between their knowledge and their level of education, years of experience. But this result come inconsistent with (Elnageeb, 2018) who stated that there was negative relation between years of experience and knowledge of nurses about nursing care.

Concerning relation between total knowledge scores and demographic characteristics among the study subjects, the present study revealed that, there is a positive statistically significant difference was found between total knowledge scores and demographic characteristics of the study subjects' sex, age and their education level respectively. This may be related to that the educational level of the staff had major impact on their ability to earn new knowledge and experience.

This result contraindicated with (Atshan and Aburghif, 2016) who indicated that there are no significant differences among nurses' knowledge with regard to their gender for both groups for all domains except general knowledge which is significantly associated with female gender. Also this result differ with (Elnageeb, 2018) who mentioned that there is no relation between level of education and knowledge of nurses about Content of infection control. Moreover this results come inconsistent with the study of (AlWily, 2015) who found that no significant association between gender of nurses and nosocomial infection domains at $p \leq 0.05$ value. In addition this result didn't come in the line with (Khedr et al., 2021) who reported that there is no significant association between nurse's knowledge and their age, sex, and marital status.

\section{Conclusion}

Based on the findings of the present study, can be concluded that, more than half of the studied sample was males, more than half of them their age ranged from 20 years to 29 years. Also the most of study subjects have unsatisfactory level of knowledge about meningitis and less than fifth have satisfactory level of knowledge about meningitis and the most of study subjects have good knowledge about universal precautions regarding meningitis.

Moreover, there are highly statistical significant differences between nurses knowledge and their years of experiences and there is a positive statistically significant difference was found between total knowledge scores and demographic characteristics of the study subjects sex, age and their education level and there no relations between attitudes score and knowledge scores both participants who have Satisfactory and unsatisfactory knowledge have a positive attitude.

\section{Recommendations:-}

1. Global educational standards should be applied to develop the nurses' skills by giving chance to nurses to participate with training sessions in developed country to improve nursing skills and receiving updates concerning care.

2. Providing educational guidelines, posters and pamphlets about meningitis and should be available at each nursing stations in wards and encourage nurses to get use from them.

3. Encourage the nurses to participate in training courses about meningitis to update their knowledge.

4. Increase nurse's knowledge and updated in pediatric unit in hospital to the current researches and guidelines by training course.

5. Further studies can be carried out in other settings and places with consideration to wide - range sample characteristics to be more representative and to get extra results. 


\section{References}

(1) Abdel-Razik, M. S., Rizk, H. I., \& Hassan, M. H. (2017). Surveillance of communicable diseases for decisionmaking in Egypt: 2006-2013. Eastern Mediterranean Health Journal, 23(6), 395.

(2) Allam, A. A., Morad, W. S., Bahbah, M. H., \& Labeeb, A. Z. (2016). Epidemiological and Clinical Study of Bacterial Meningitis in Menoufiya Governorate. Med. J. Cairo Univ, 81(2.(

(3) Al-wily, M.A.S. (2015). Effectiveness of Educational Program on Nurses Knowledge toward Nosocomial Infection at Neonate Intensive Care Units in Baghdad Hospitals, A Thesis Submitted By, University of Baghdad / college of nursing. Published master thesis. pp.79-88.

(4) Atshan,R.S \& Aburghif L.F,(2016) : Effectiveness of an Educational Program on Nurse's Knowledge toward Children with Meningitis at Pediatric Teaching Hospitals in Baghdad City. International Journal of Scientific and Research Publications, 6( 9),pp346-356.

(5) Barrera-Cancedda, A. E., Riman, K. A., Shinnick, J. E., \& Buttenheim, A. M. (2019). Implementation strategies for infection prevention and control promotion for nurses in Sub-Saharan Africa: a systematic review. Implementation Science, 14(1), 111 .

(6) El Kareh, A., El Hage, S., Safi, S., Assouad, E., Mokled, E., \& Salameh, P. (2020). Epidemiology of bacterial meningitis in Lebanon from 2011 to 2019. Journal of Clinical Neuroscience, 81, 32-36.

(7) Elnageeb, M. M. (2018). Shandi University, National University, 38(3), 291-301.

(8) Gawad, A. (2017). Assessment of knowledge about standard precautions and nosocomial infection among nurses working in hospitals of Sana'a city, Yemen. International Journal of Caring Sciences, 10(1).

(9) Hasbun, R., Rosenthal, N., Balada-Llasat, J., Chung, J., Duff, S., Bozzette, S., . . . Ginocchio, C. C. (2017). Epidemiology of meningitis and encephalitis in the United States, 2011-2014. Clinical infectious diseases, 65(3), 359363 .

(10) Hassan, H., Malk, R., Abdelhamed, A., \& Genedy, A. (2020). Infection Control Knowledge and Practices: Program Management in Labor Units According to Standard Infection Control Precautions in Northern Upper Egypt. American Journal of Nursing Research, 8(4), 412425 .
(11) Hattab, W. A. A., Kadhim, A. J., \& Abdulwahhab, M. M. (2017).Impact of Years' Experience upon Nurses' Knowledge and Practice concerning Infection Control at Critical Care Units in Baghdad City 261, 113234.

(12) Kafl, R. H. and M. H. Bayoumi, (2019). "Nurses' Performance towards Care of Neonatal Meningitis: Effect of an Educational Program. 18(1), 1-12.

(13) Mohammed, H. A., Mohammed, M. A., \& Ahmed, N. A. (2019). Effect of Teaching Program Regarding Care for Acute Meningitis on Nurses Performance at Emergency Unit. Assiut Scientific Nursing Journal, 7(16), 91-100 .

(14) Moyo, G. M. (2013). Factors influencing compliance with infection prevention standard precautions among nurses working at Mbagathi district hospital, Nairobi, Kenya, University of Nairobi,18(2), 773.

(15) -Nguc, K. S., \& Halim, S. A. (2018). Anterior spinal cord syndrome as a rare complication of acute bacterial meningitis in an adult. Case Reports, 2018, bcr-2018226082.

(16) Obaid, B., Hussein, A., \& NOORI, K. (2016). Nurses' Knowledge Concerning Neonatal Sepsis In Neonatal Intensive Care Units At Pediatric Teaching Hospitals In Baghdad City. Asian Academic Research Journal of Multidisciplinary, 3(7), 56-65.

(17) Oladele, R. O., et al. (2020). "Tackling cryptococcal meningitis in Nigeria, one-step at a time; the impact of training." Plos one 15(7): e0235577.

(18) World Health Organization, W. H.O. (2019). Defeating meningitis by 2030: baseline situation analysis. World Health Organization .

(19) Rajan, K. E., \& Karen, C. (2019). Neonatal Bacterial Infection. Pocket Guide to Bacterial Infections, 147.

(20) Shivani, D., \& Rashmi, Y. (2019). A Study to Assess the Effectiveness of Structured Teaching Programme on Knowledge Regarding Universal Precaution among Basic B. sc Nursing First Year Student of State College of Nursing, Dehradun, Uttarakhand. International Journal of Nursing Education, 11(3).

(21) Zaki, N. A.-E. and A. A. Hussien, 2017. Impact of an Educational Program on Improving Nurses Knowledge and Practice concerning caring for Children with Meningitis, Egyptian journal of health care,11(4), 518.

(22) Zelano, J., \& Westman, G. (2020). Epilepsy after brain infection in adults: A register-based population-wide study. Neurology, 95(24), e3213-e3220. 